\title{
La Ciudad Universitaria de Madrid y el ideal panhispánico
}

\author{
Sofia Dieguez Patao *
}

El tema de la Hispanidad no es nuevo en el periodo de postguerra sino que se remonta al pensamiento regeneracionista de principios del siglo $x x$, cuando los intelectuales españoles creian que la identidad cultural común era un elemento básico a través del cual podia mitigarse la decadencia internacional de España. Lo que se hace en los años cuarenta es ajustar ese ideal a unos nuevos intereses y objetivos.

La politica cultural hacia lberoamérica sirvió como pantalla que ocultaba objetivos que, muchas veces, revasaban el marco meramente cultural para cubrir otros campos de actividad diplomática y adquirir múltiples ramificaciones de la acción politica.

Como ha indicado M. Espadas Burgos ': "La Hispanidad, como afirmación ideológica y como vehículo de propaganda, fue uno de los escasos cauces de proyección exterior que le quedarian al régimen durante los años de aislamiento impuesto por la condena internacional».

El documentado estudio de L. Delgado ${ }^{2}$ desvela además cómo esta política cultural fue fluctuando en los años cuarenta de acuerdo con el desarrollo que iban teniendo los acontecimientos. Concluida la Segunda Guerra Mundial los llamamientos a estrechar los lazos con Iberoamérica se hicieron más intensos y la politica de la Hispanidad se convirtió en uno de los elementos primordiales utilizados por la diplomacia franquista para romper el cerco internacional de cara al exterior y al interior del país.

* Profesora Titular del Departamento de Arte Contemporáneo UCM.

Espadas Burgos, M., Politica franquista y politica exterior, pág. 281. Madrid 1987.

${ }^{2}$ Delgado, L., Diplomacia tranquista y politica cultural hacia iberoamérica, 1939-1953. C.S.I.C., 1988 , 
Retomar la visión católico-integrista de la Hispanidad, asentada sobre la "comunidad espiritual" y los vínculos culturales, distanciándose de las reminiscencias intervencionistas de sesgo falangista, suponia un primer paso. La proyección ideológica basada en la afinidad religiosa y cultural con Iberoamérica constituirá en el futuro el factor de integración más potente en la pregonada identidad colectiva.

La conmemoración de la fiesta de la Hispanidad, el 12 de octubre - Día de la Raza-, solía ir acompañada de importantes actos, entre los que no faltaban las inauguraciones. Dos de las más significativas tuvieron como escenario la Ciudad Universitaria, son las correspondientes a los años $1943^{3}$ y 1945 en que se procedió a la inauguración de la mayoria de los edificios destruidos durante la guerra civil.

En el discurso pronunciado por el general Franco en 1943 se dedicaban unas palabras al tema de América: "La fiesta de hoy, aniversario del más grande de los acontecimientos de la Historia, nos impulsa a dirigirnos desde aqui, desde este Centro espiritual de cultura y de ciencia, a nuestros hermanos del otro lado del mar. Ellos forman con nosotros la comunidad hispánica, estrechamente unida por los vinculos de la Religión y el idioma. Para las juventudes hispanoamericanas que quieran cursar sus estudios en la vieja Europa, madre de la civilización, se ha hecho también esta Ciudad Universitaria, la cual desde el primer día de su feliz iniciativa, ya acarició la ilusión de servir de albergue y hogar a cuantos hijos de la América hispana desearan laborar en armonia con nuestros maestros y discipulos, en pro de la común cultura que nos ha definido en la Historia con caracteres espirituales fraternos" ${ }^{4}$ (fig. 1).

En el discurso se resalta fundamentalmente el elemento cultural con que queria asociarse el concepto de Hispanidad y se aludia también a la inauguración simbólica del comienzo de la construcción del Museo de América.

También es relevante la celebración del Día de la Hispanidad de 1945. En el transcurso de la jornada se inauguraron tres nuevos edificios en la Ciudad Universitaria ${ }^{5}$. Aprovechando este escenario, el Ministro de Educación Nacional, José Ibáñez Martín reiteraba el ofrecimiento a los estudiantes iberoamericanos para que acudieran a formarse en la Universidad

\footnotetext{
${ }^{3}$ El Jefe del Estado inauguró los edificios de la Facultad de Filosofia, Ciencias y Farmacia, Escuela de Arquitectura, Escuela de Ingenieros Agrónomos, Colegio Mayor Ximénez de Cisneros, Pabellón de Gobierno y Campos de Deportes.

- Franco, F., Discurso pronunciado por S.E. el jefe del Estado, Caudillo de España, en la Ciudad Universitaria de Madrid, pág. 11. Octubre, 1943

${ }^{5}$ Escuela de Montes y los edificios de Estomatología, Ciencias Físicas y Matemáticas.
} 


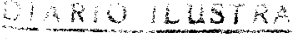 ODE INFORMA CUON GENERAL 25 CENTIMOS Q
}
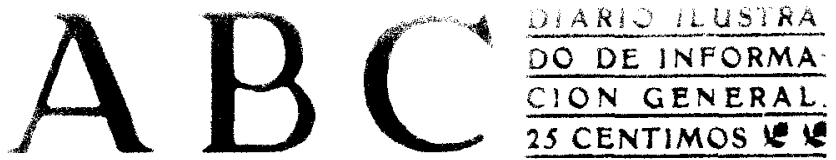

FUNDADO EN

\author{
905 POR D. TORCUATO
}

1. UCA

DE TENA
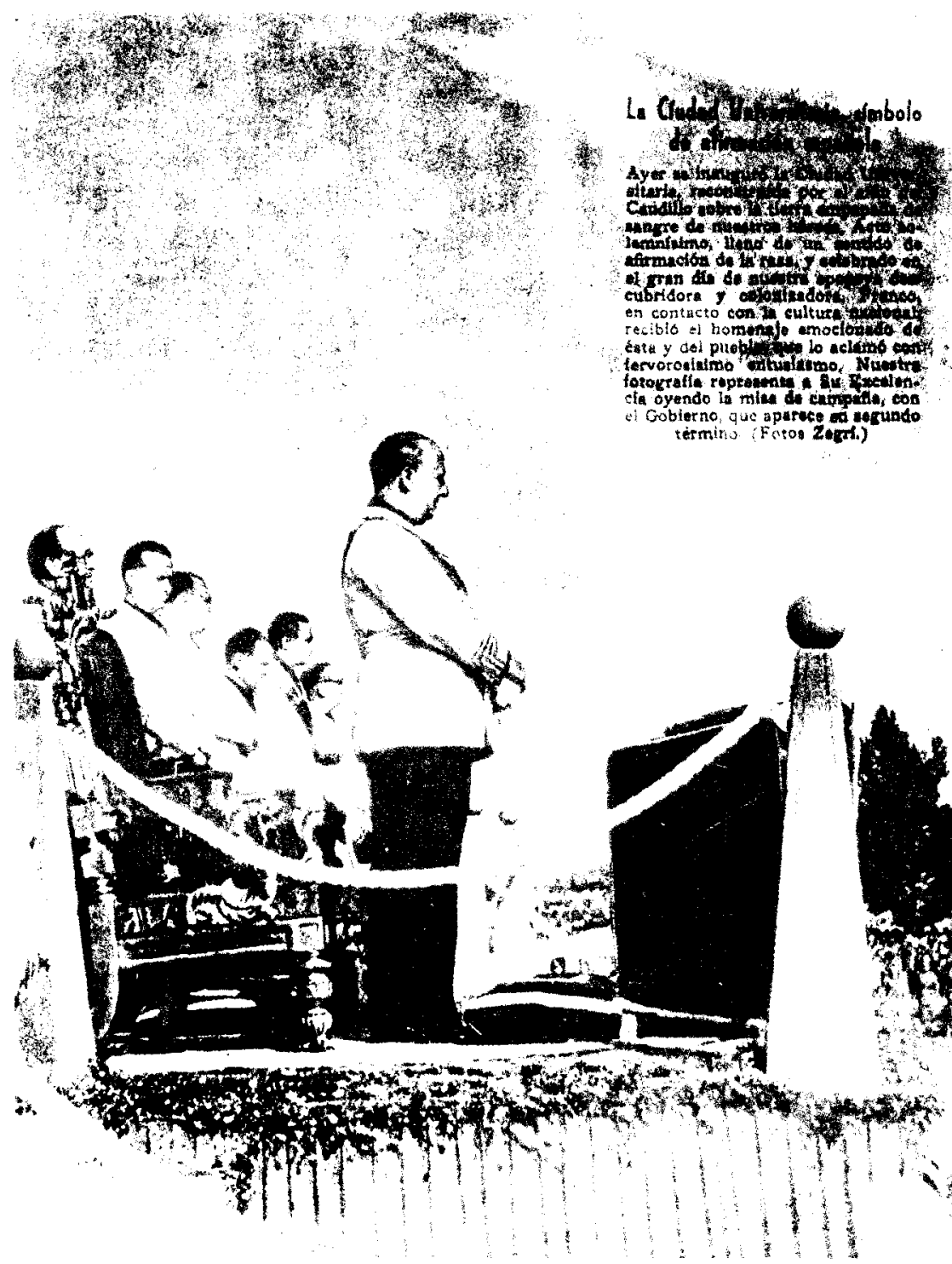

Fig. 1. Actos celebrados en la ciudad Unversitand do Madnd. A.B.C. igas 
madrileña que — dijo — «habia sido concebida pensando en ellos, puesto que España aspiraba a consolidar los vínculos seculares que unian a los distintos paises de lengua hispana" ${ }^{6}$.

El fasto otorgado a la conmemoración del día de la Hispanidad es reflejo de la transcendencia que se concedía a esta dimensión de la acción exterior española, siendo frecuentes en los discursos los alegatos a la hermandad hispanoamericana.

Es en este contexto social donde debemos insertar la construcción - muy significativa - del Museo de América, el Instituto de Cultura Hispánica y el Colegio Mayor de Nuestra Señora de Guadalupe, iniciados todos ellos en la década de los años cuarenta en el recinto universitario.

La Ciudad Universitaria de Madrid, fundada en 1927 por Alfonso XIII, constituye en si misma uno de los capitulos más interesantes de la historia urbana de la ciudad y, además, podemos considerarla como un muestrario perfecto de las corrientes arquitectónicas desde los años veinte hasta nuestros días. A estos valores añade una gran variedad de significaciones (simbólicas, sociales, históricas, etc.) que la hacen merecedora de una atención especial y permiten una continua reelectura.

De los cuatro periodos en que puede dividirse su historia: Monarquia, República, Postguerra y Desarrollismo, nos centramos en los años cuarenta, aquellos que Ramón Tamames caracteriza como de «autarquia y estancamiento".

Este nuevo período imprimió su sello ideológico en la Ciudad Universitaria. El Gabinete Técnico, bajo la dirección de los arquitectos Modesto López Otero y Pedro Muguruza, simultaneo la reconstrucción de los edificios destrozados por la guerra y la elaboración de un nuevo proyecto de conjunto.

El anterior, aprobado durante la Monarquia y continuado en la República, seguia el modelo de los "campus" norteamericanos y estaba estructurado en función del viario y de la división del conjunto en cuatro grandes grupos o zonas: el mayor, o principal, formado por el Rectorado, Paraninfo y Gran Biblioteca Universitaria, juntamente con la Facultad de Filosofía y Letras, Ciencias y Derecho; el segundo, el grupo médico; el tercero, el de Bellas Artes y el cuarto, que incluia residencias de estudiantes y campos de deportes. Este último era el más informal y en él los edificios se agrupaban espontáneamente.

${ }^{6}$ Vid. Arriba, 13 de octubre de 1945 e Informaciones, 12 de octubre de 1945. 
Reconstruir lo destruido fue la tarea prioritaria en los primeros años de la postguerra. Justamente en la Ciudad Universitaria esta labor tenia un valor especial pues en ella se habia situado uno de los frentes más prolongados de la guerra civil, evaluándose en un 40 por 100 los destrozos producidos. La reconstrucción se iniciará a partir del Decreto, firmado por el general Franco, de 1940. Se adoptó una actitud pragmática de forma que se impuso la opinión de que lo más oportuno era reconstruir ateniéndose fielmente a lo anterior. Se siguió, pues, una línea de continuidad con el período precedente, y no prosperó la idea de convertir las ruinas en un "recuerdo permanente de los muertos".

Pero junto a esta política arquitectónica continuista, a la que no es ajeno el hecho de que López Otero se mantuviese en la dirección de las obras y que conservase en el equipo a todos aquellos arquitectos que habian participado en la etapa anterior, y que no se habian exiliado, nos interesa incidir fundamentalmente en los cambios que se operan a nivel de concepción.

El cambio de orientación que se dio en la Ciudad Universitaria se refleja en dos niveles: urbanisticamente, en la creación del itinerario representativo, y, arquitectónicamente, en el estilo que se impuso en los edificios proyectados y construidos en los años cuarenta.

Es importante desentrañar la carga simbólica que alcanza la Ciudad Universitaria y, más especificamente, la relación entre el concepto de la Hispanidad y el hecho de que sean justamente tres edificios relacionados con América uno de los escasos ejemplos de arquitectura construida en Madrid en la postguerra, cuando tantos proyectos quedaron en el papel, sin llegar jamás a formalizarse («Fachada Representativa del Manzanares", "Via triunfal del Paseo de la Castellana»...).

La Ciudad Universitaria estaba concebida como una pieza de un puzzle más amplio: el de Madrid, "Capital del Imperio". Era, según la terminología de la época, un "órgano de capitalidad", es decir, un núcleo de carácter representativo ${ }^{7}$.

Como señalábamos hace unos años ${ }^{8}$ "el nuevo programa se basaba en la idea de crear un centro universitario que exaltara a través de edificios conmemorativos los valores transcendentales de la Ciudad Universitaria, en especial la victoria y el cambio de régimen politico".

\footnotetext{
'Diéguez Patao, S., Un nuevo orden urbano. "El Gran Madrid" (1939-1951). MAP-Ayuntamiento de Madrid, 1991.

${ }^{8}$ DiÉguez PATAO, S., "Destrucción, reconstrucción y nuevo carácter de la Ciudad Universitaria. Años cuarenta", en La Ciudad Universitaria de Madrid, vol. I. COAM-UCM, pág. 60, 1988.
} 


\section{THE MADRID UNIVERSITY CITY}

Aras A: I, Angembly Fall and Rectorate; 2 , Facully of Law and of Philosophy and Letters; 3. Faculty of Science.-Ares B: 4, Faculty of Pharuacy; 5, Faculty of Medicine; 6, School of Dentistry; 7, Clinical Hospital; 8, School of Architecture; 9, "Casa de Velázqucz"; 10, School of Forest Engineering; 11, School of Agriculfural Engineering; 12, School of Naval Enginecring; 13, Amcrican Mnseum; 14, $\mathrm{P}_{\mathbf{2}}$ lace of the Council of Hispanity; 15, Offices; 16, "Ximénez de Cinneros" Residential College; 17. Sports Grounds; 18, Botanical Garden; 19. Central beating station; 20, Astranomical Observatory; 21, Raihwaymen's Orphon's School; 22, "Isabel la Católica" Residential College: 23, Stadium; 24, Reservair for Aquotic Sports; 25, Church of St. Thomas Aquinix ; 26, S. E. U.; 27, Professor's Flats ; 28, Viaduct; 29. Momumeni to Franco; 30, Monument to Jose Antonio Primo de Rivera; 31, Monument to Cardiaal Cisneros; 32, Monumental Fountain; 33, Monument to Cajal; 34, Entrance Gate of Botanical Garden; 35, Monument to Alphonso XIII: 36, Mounment to Menondez $v$ Pelayu; 37, Snall Palace.

\section{LA CITE UNIVERSITAIRE DE MADRID}

Zonte A: 1, Grand Amphithéàtre et le Rectorat; 2, Facullè de Droit et Faculté des Lettref; 3, Fuculté des Sciences.--Zone B: 4, Faculté de Pharmacie; 5, Faculté de Médecine; 6 , Ecole d'Odontolozie; 2, Fopital Clinique; 8, Ecolo d'Architecture; 9, Cosa Vulázquez; 10, Ecole des Ingénicurs des Eaux et Foréts; 11, Ecole des Ingéfieurs Agronomes; 12, Ecole des Lrgénieurs de Constructions Navales; 13 Musée d'Amérique; 14, Pulois du Conscil de l'Hispan nité; 15, Pavillon de rAdministration et bureaux; 16, Colegio Mayor Ximenez de Cisneros: 17, Terroins de Sports; 18, Jardin Botanique; 19, Centrale thermique; 20, Observaloire Astronomique; 21 , Collège des Orphelins des Chenins de For de l'Etat; 22, Colegio Ma. yor Isabel la Católica; 23. Stade; 24, Bassin des sports aquatiques; 25 , Eylise de St.-Thomas d'Aquin; 26, S. E. U.; 27 , Résidence des professeurs; 28, Viaduc; 29, Monument du Géné ral Franto: 30. Monument de José Antonio Primo de Rirera; $3 I$, Monument du Cardinal Cisneros; 32, Fontaine monumentale; 33, Monument de Cajal; 34, Portique d'entrćc au Jardin Botanique: 3.i, Monument d'Alphonse XIII; 36, Monument de Mencidez y Peloya; 37, Petit palais.

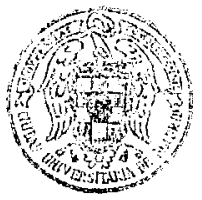

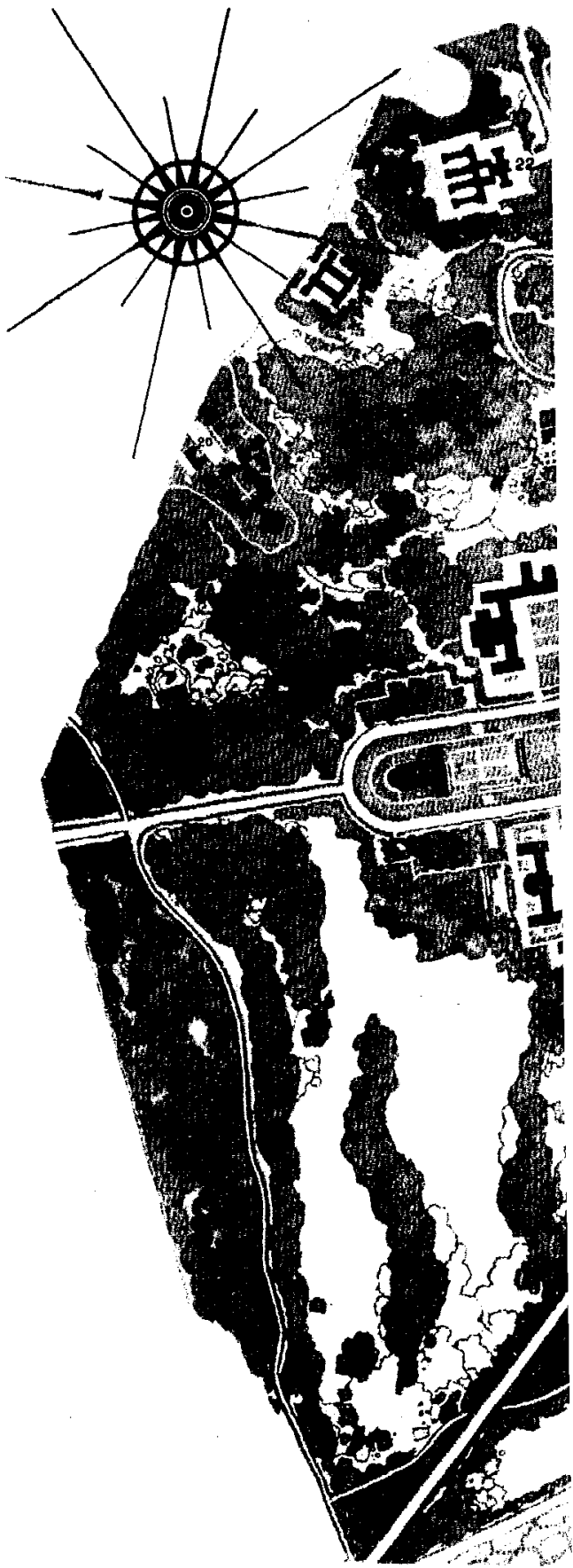


ig. 2. Plano de conjunto de la Ciudad Universitaria. Folleto editado por la Secretaria de la Junta de la Ciudad Universitaria. 1947

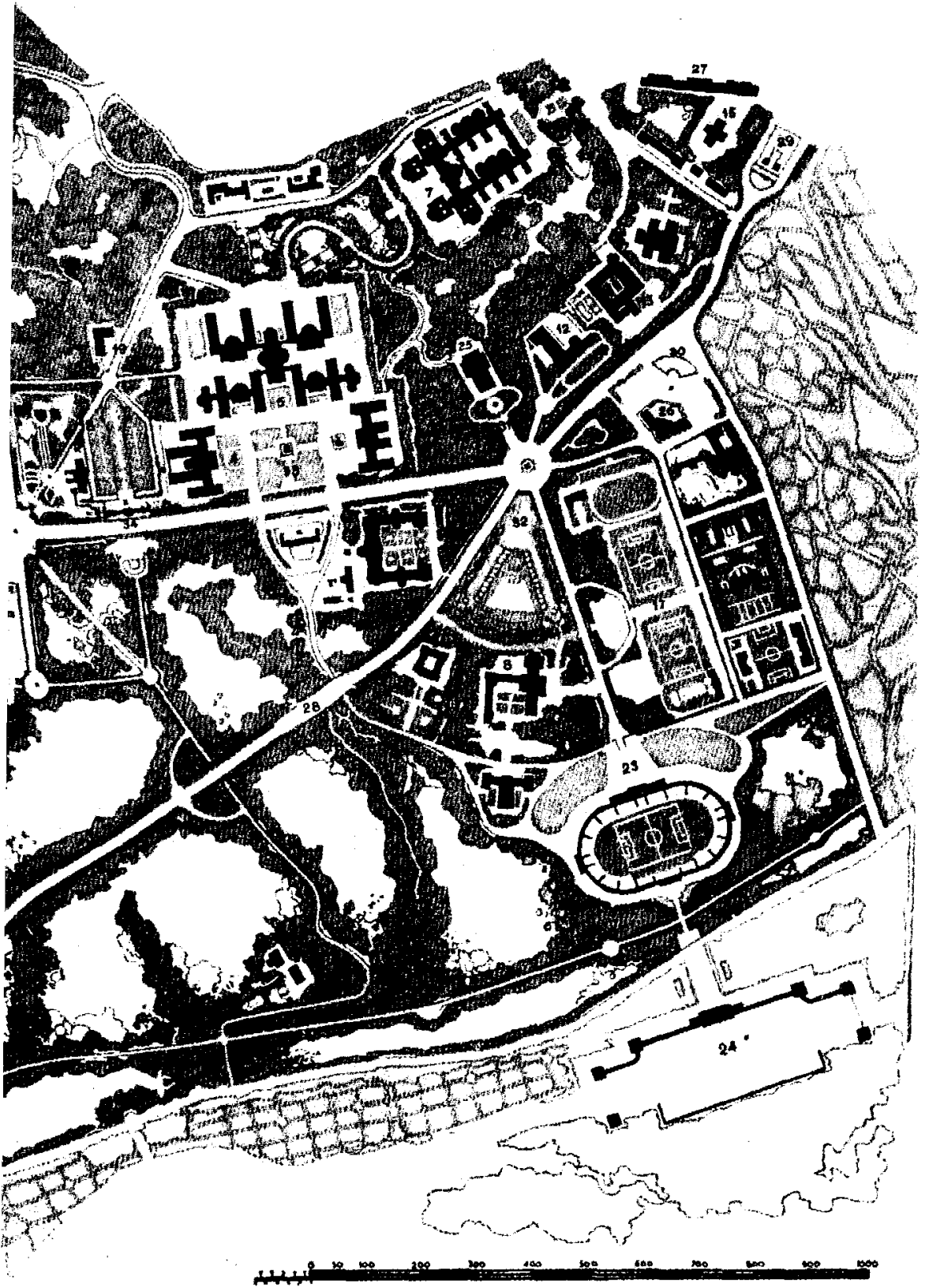




\section{THE UNIVERSITY CITY OF MADRID}

\section{LA CITE UNIVERSITAIRE DE MADRID}

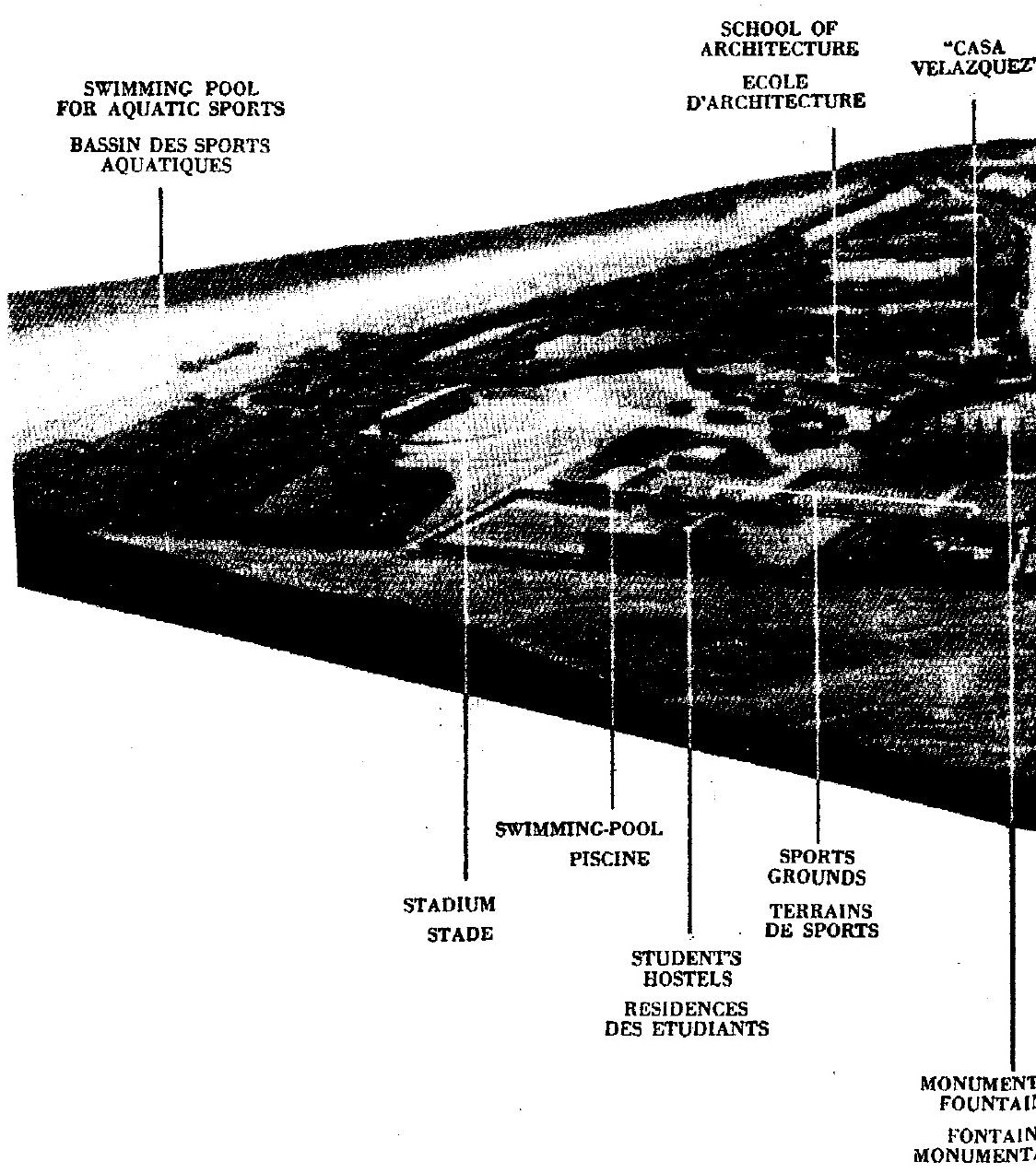

Fig. 3. Maqueta de la Ciudad Universitaria. Reproducida en el Folleto editado por la Junta de la Ciudad Universitaria, 1947 
En un folleto editado por la Junta Constructora de la Ciudad Universitaria de Madrid, de 1943, se incidia en el viario de carácter representativo: "Los caminos son más adecuados si las masas circundantes no encuentran dificultades, además del placer espacial. Cuanto más se parezcan las calles de la ciudad a las calles militares, tanto más adecuadas a los desfiles, tiene un poder sugestivo en las masas. $Y$ se ven y se ponen en contacto esas masas escolares y se funden" (figs. 2 y 3 ).

Este recorrido, cargado de simbolismo, se iniciaba en la Plaza de la Moncloa, el único conjunto de la proyectada "Capital del Imperio" que llegó a configurarse ${ }^{9}$, el Arco de Triunfo conmemorativo de la Cruzada y de ensalzamiento de la figura del general Franco, y continuaba con los edificios del Museo de América y el Palacio de la Hispanidad (posterior Instituto de Cultura Hispánica) representativos del ideal Panhispánico. Más allá la Casa del SEU y la estatua de José Antonio recordarian el papel de la Falange. El ideal nacionalcatolicista se afirmaba no sólo en el Templo de Santo Tomás de Aquino, sino también en la obligación de que cada edificio escolar contase con una capilla propia. Todo culminaba en el conjunto de Gran Paraninfo y Rectorado para el que López Otero estuvo ensayando durante años fórmulas arquitectónicas y que nunca llegó a construirse ${ }^{10}$.

Tanto el Museo de América como el Instituto de Cultura Hispánica ocupaban, pues, un lugar destacado en la organización de la Ciudad Universitaria (fig. 4).

El primero tiene un antecedente claro en el ambicioso proyecto, no realizado, del "Museo Biblioteca de Indias»", que se pensó levantar en la Ciudad Universitaria y cuyos planos fueron encargados al arquitecto Luis Lacasa. Nunca se hizo la más minima mención de este antecedente, impulsado por el gobierno de la República, y que sin duda está en la base del Museo de América, creado por Decreto de 1 de mayo de 1941, con el fin de "reconstruir la gesta heroica del descubrimiento de América".

En el Discurso pronunciado por el general Franco en octubre de $1943^{12}$ se menciona este edificio "como prenda de esta nueva etapa de acercamiento cultural de España y los pueblos americanos, quiere el Estado inaugurar hoy simbólicamente el comienzo de la construcción del

Diéguez Patao, S., “La Moncloa". en Madrid. Ed. Espasa Calpe, 1980.

También se proyectó la llamada "Fuente Monumental» dedicada a las Artes españolas, "El Monumento al Cardenal Cisneros", el "Monumento a Alfonso XIll».

Vid. Cabello Carro, P.. Coleccionismo americano indigena en la España del siglo xvitu. Madrid. Ed de Cuitura Hispánica, 1989.

Franco. F. Op. cit., pág. 12 


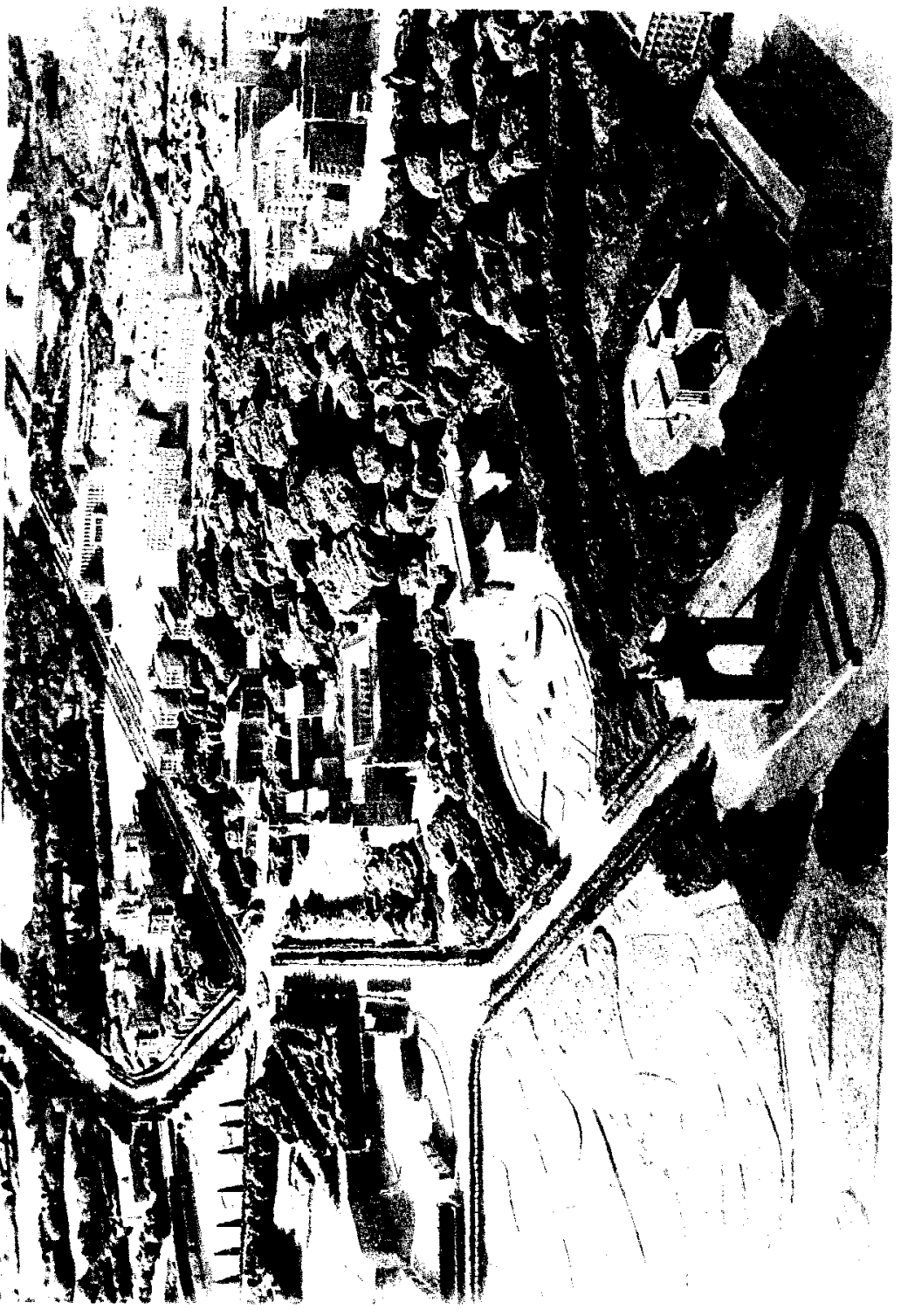


Museo de América, que muy pronto se alzará en el corazón de esta misma Ciudad Universitaria, como gallardo emblema conmemorativo y, a la par, como indice perpetuo de nuestra comunidad espiritual".

Un año más tarde, en 1944, se iniciaron las obras de explanación del edificio proyectado por los arquitectos Luis Moya Blanco y Luis Martínez Feduchi. Su emplazamiento en el recinto universitario era privilegiado: en contacto casi directo con la ciudad, sobre una loma y próximo al previsto palacio de la Hispanidad.

Los dos estaban concebidos de forma que constituyesen un conjunto armónico. La composición de masas del Museo se proyectó teniendo en cuenta su relación con el terreno, los accesos y la silueta de conjunto de ambos edificios.

El Museo fue organizado para responder a tres funciones: Recepción y Representación (vestíbulos, salón de honor, capilla y sala de conferencias): a Trabajo la segunda (biblioteca, dirección, secretaria, locales para investigadores, almacenes, talleres, etc.); la tercera, Exhibición, constituida por las salas del museo propiamente dicho (fig. 5).

La primera parte se compone de dos plantas y ocupa el ala del mediodia del edificio. En la capilla, los autores del proyecto subrayan que fue trazada a la manera española del siglo XVII, y tiene en su crucero una cúpula en la que se recogian siluetas y temas americanos, incorporados a la arquitectura general del edificio, que "es a la manera española del 1600" (fig. 6).

La parte destinada a trabajo ocupa un pabellón adosado por el Poniente al edificio principal. Este pabellón está organizado en torno a un "patio de tipo andaluz y americano".

El Museo propiamente dicho se desarrolla en dos plantas, en forma de $U$, cerrado por tres lados del claustro, pues un cuarto lo ocupa el gran Salón de Recepciones (fig. 7).

El edificio se plantea en términos de composición como un convento español o americano de los siglos XVI-XVII. La planta se organiza en torno a un gran patio a modo de claustro conventual, al que se adosa la iglesia a un costado y un cuerpo delantero, en torno a un patio pequeño, a modo de hospederia donde se instalarian las viviendas del director y el conserje.

La escasez de hierro y cemento en la España de la postguerra hizo que los arquitectos optaran por un sistema constructivo de tradición artesanal catalana, aunque dificil: las bóvedas tabicadas ${ }^{13}$.

\footnotetext{
13 Luis Moya publicó en 1947 el libro Bóvedas Tabicadas en el que explica el fundamento de este sistema y su relación con la tradición española.
} 


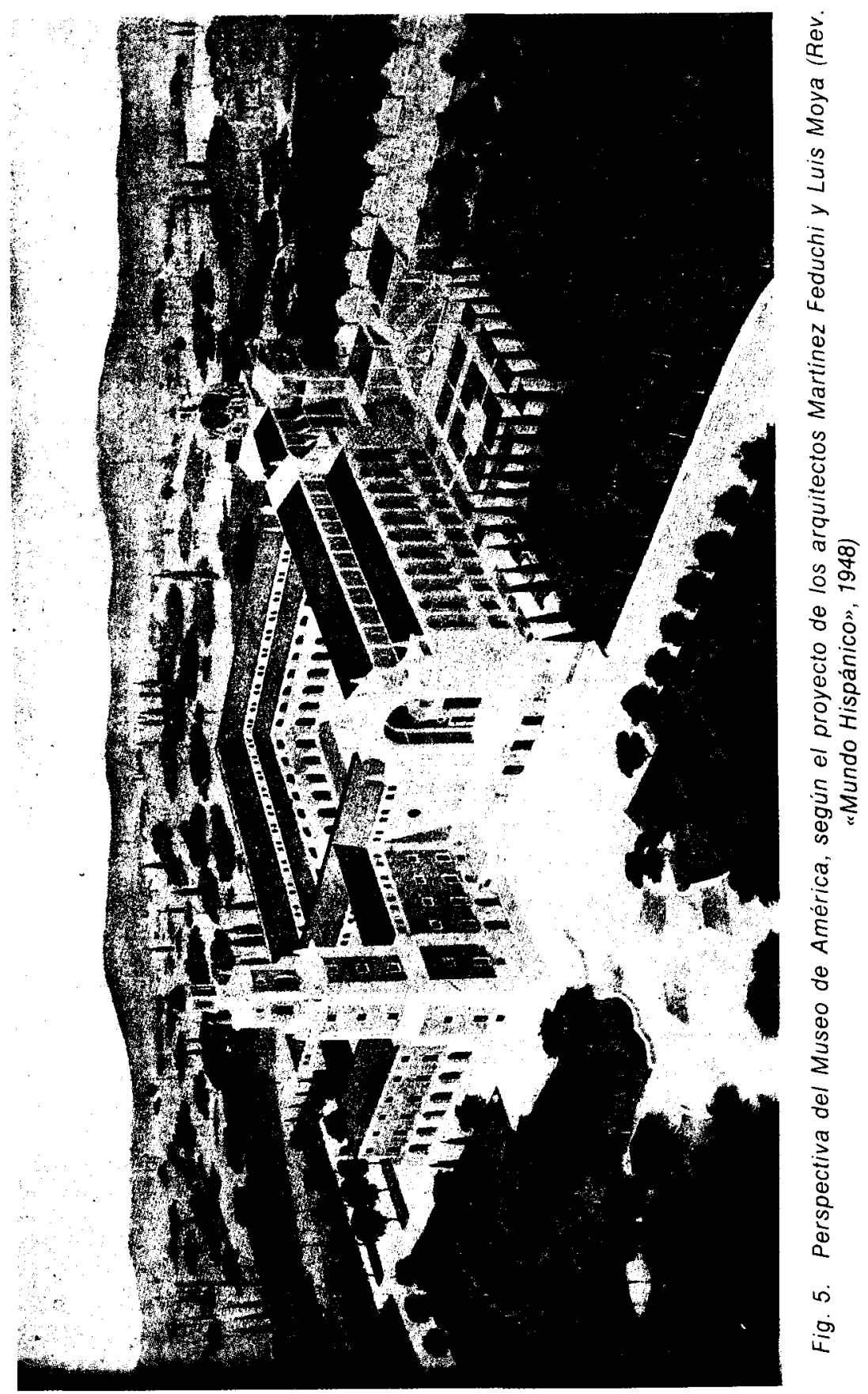



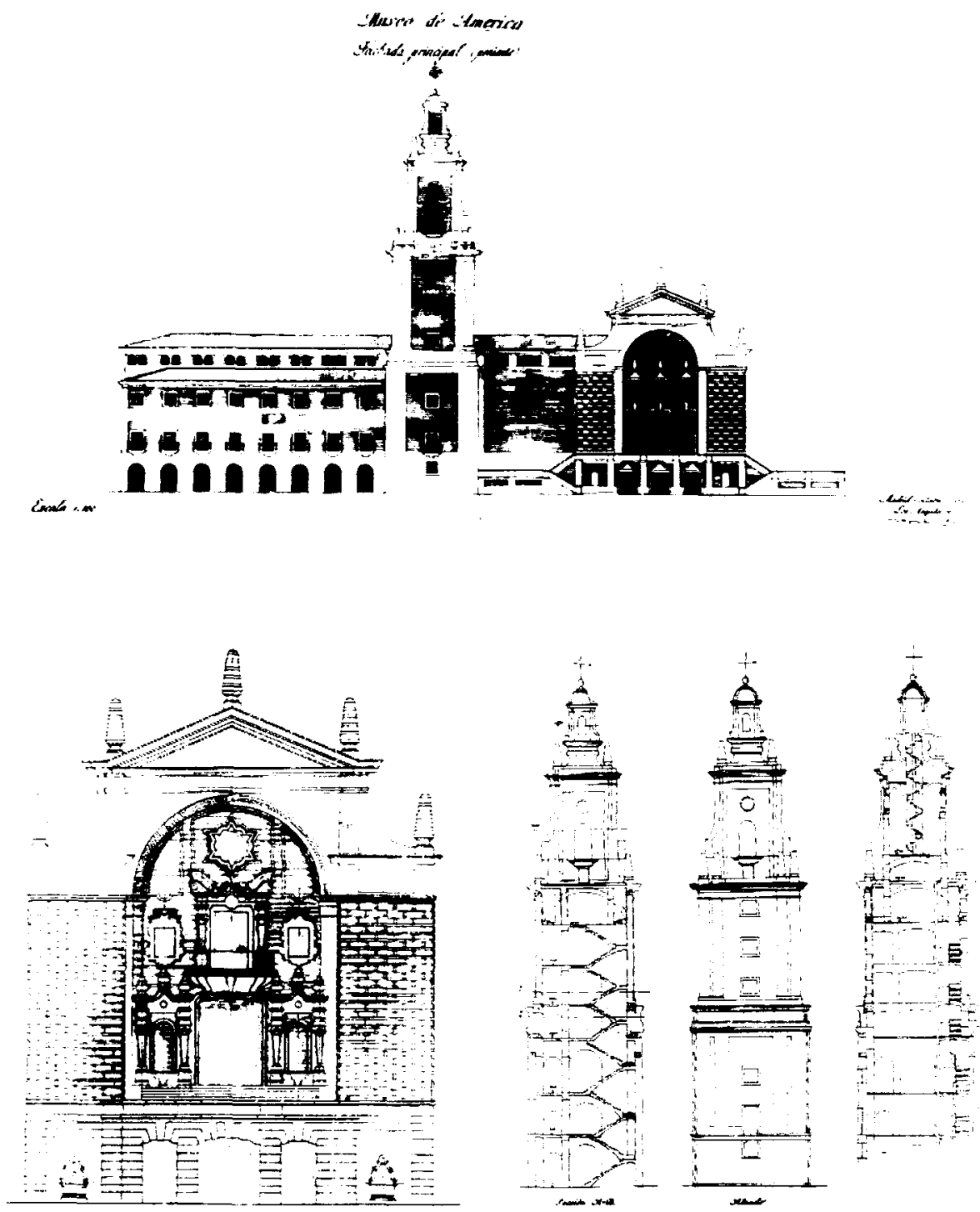

Fig. 6. Museo de America. L. Martinez Feduchi y L. Moya, 1942

Este sistema solventaba dicha dificultad y daba a la construcción una fisonomía especial «de acuerdo con las construcciones españolas y americanas del Siglo de Oro" ${ }^{14}$. Luis Moya subraya que este sistema de bó-

${ }^{14}$ Mora, L., “El Museo de América», Arriba, 1945. 


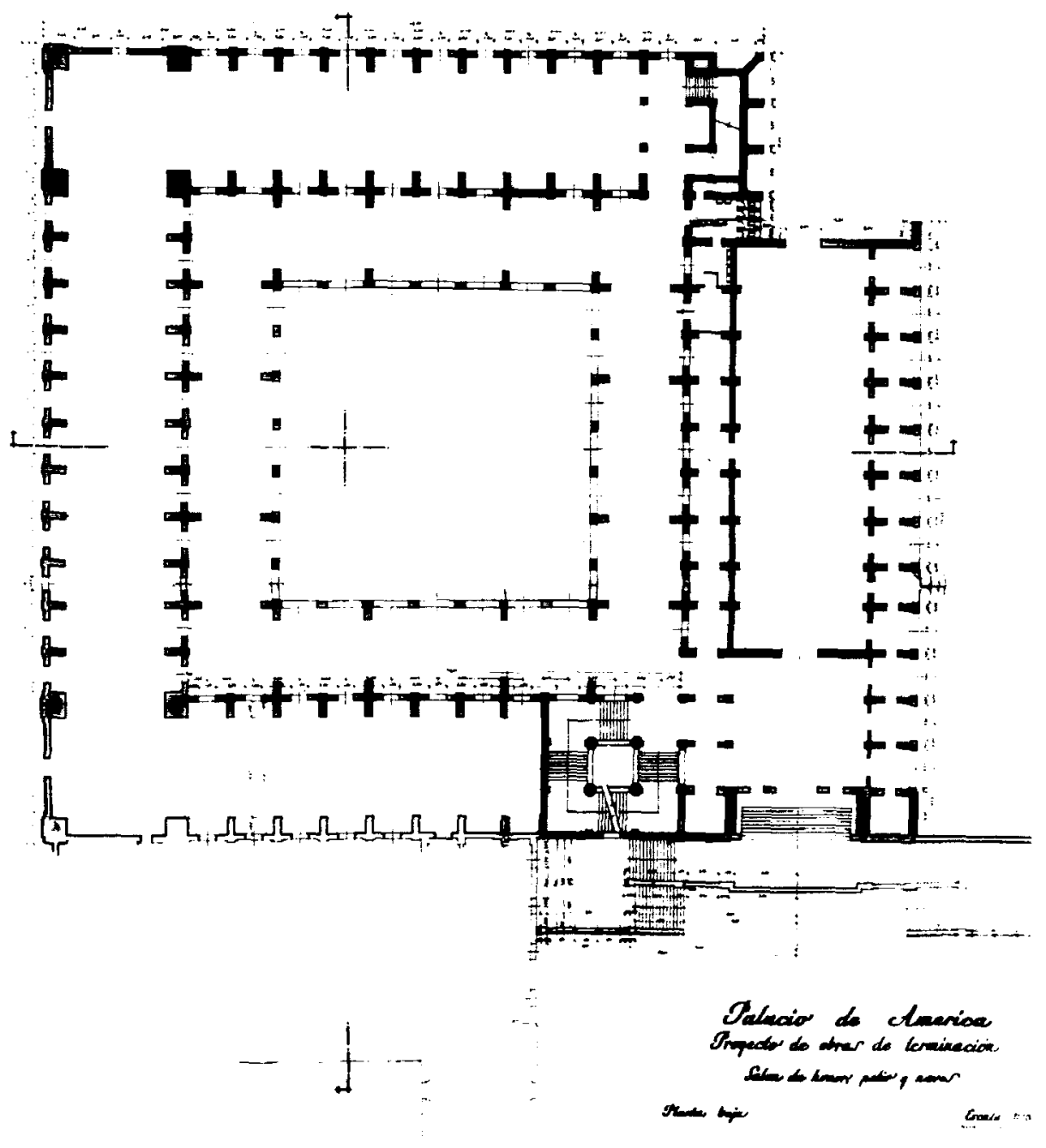

Fig. 7. Museo de América. Planta del patio y naves, 1942

vedas es el mismo que emplearon los arquitectos españoles en la construcción de edificios caracteristicos de América, con ejemplos frecuentes en México, Guatemala, Colombia, Perú, Argentina, etc.

Las fachadas se revestian de ladrillo fino al descubierto, con todas las pilastras, impostas, cornisas, abultados y adornos de cualquier clase construidos en piedra. En el interior se dejarán las bóvedas y muros simplemente guarnecidos, blanqueados y pintados al temple. 
Pero el aspecto más interesante de este edificio es subrayar la opción estilistica que se adoptó: la tradición clásico-barroca de la América española. «El estilo arquitectónico del edificio - declaraban sus autores en el diario Arriba en 1945- tras de varios trabajos y estudios, decidimos que fuera como un resumen de la arquitectura española que dio origen a la colonial americana. Con esto cumplíamos un doble fin. De un lado, ningún edificio más indicado que el Museo de América para reproducir en su traza arquitectónica el característico orden de los mejores edificios coloniales construidos por los arquitectos españoles en América. $Y$, por otra parte, éste nos resolvia un problema muy importante en los actuales momentos de España: el de la escasez de hierro y cemento para su construcción».

Esta obra cabria interpretarse -como hace A. Capitel ${ }^{15}$ - como "otra muestra de lo que será el papel de Moya durante los primeros años de la década, cuando el Estado le da ocasiones para definir lo que puede ser la "arquitectura nacional", la "Academia española"»" ${ }^{16}$ (fig. 8).

El Instituto de Cultura Hispánica, diseñado por Luis Martinez Feduchi, por encargo del Ministerio de Educación Nacional, sustituia al palacio de la Hispanidad y se ubicaba en el solar previsto para éste. Iniciadas las obras en 1940 quedarian finalizadas en 1951.

El edificio, con planta de $T$ invertida, se organiza en torno a un patio central. A un lado y otro del vestibulo se sitúa una sala de exposiciones y un centro de reuniones. En el eje central se colocaba la biblioteca, y, a ambos lados del patio, las distintas dependencias destinadas a la administración.

Creado para potenciar las relaciones culturales entre España y América, la importante carga simbólica que tenía el edificio se refleja perfectamente en la articulación de la fachada. Luis Martinez Feduchi, autor junto a $V$. Eced de uno de los edificios más significativos del expresionismo español, el Capitol de la Gran Vía, se muestra en esta obra absolutamente acomodaticio con las directrices y el ambiente cultural de la postguerra española (fig. 9).

En la fachada, de tres cuerpos con el central destacado, se alterna la piedra del basamento con la fábrica de ladrillo en el resto. El cuerpo cen-

${ }^{15}$ CaPitel, A., La arquitectura de Luis Moya Blanco. COAM, pág. 83, 1982.

16 Desde 1984 se lleva a cabo un proyecto de restauración y dotación de nuevas instalaciones, aún no concluido, bajo la dirección de Antón Capitel que, en vez de plantearse un rompimiento con las directrices del proyecto de 1942, acepta el legado de Luis Moya y Martínez Feduchi sin modificaciones sustanciales, procurando mimetizarse con to preexistente. 

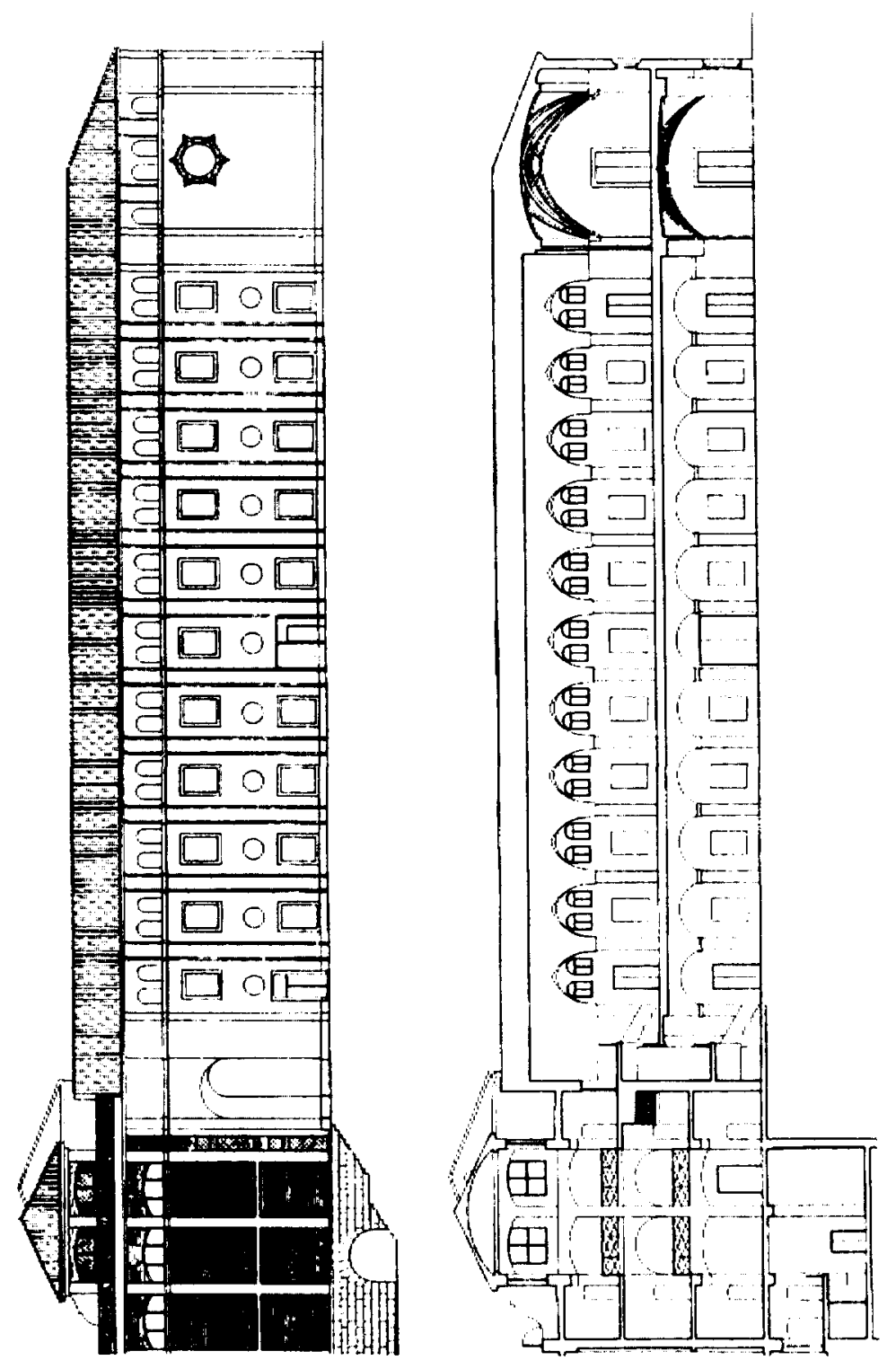

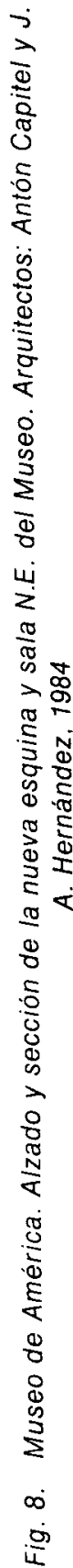




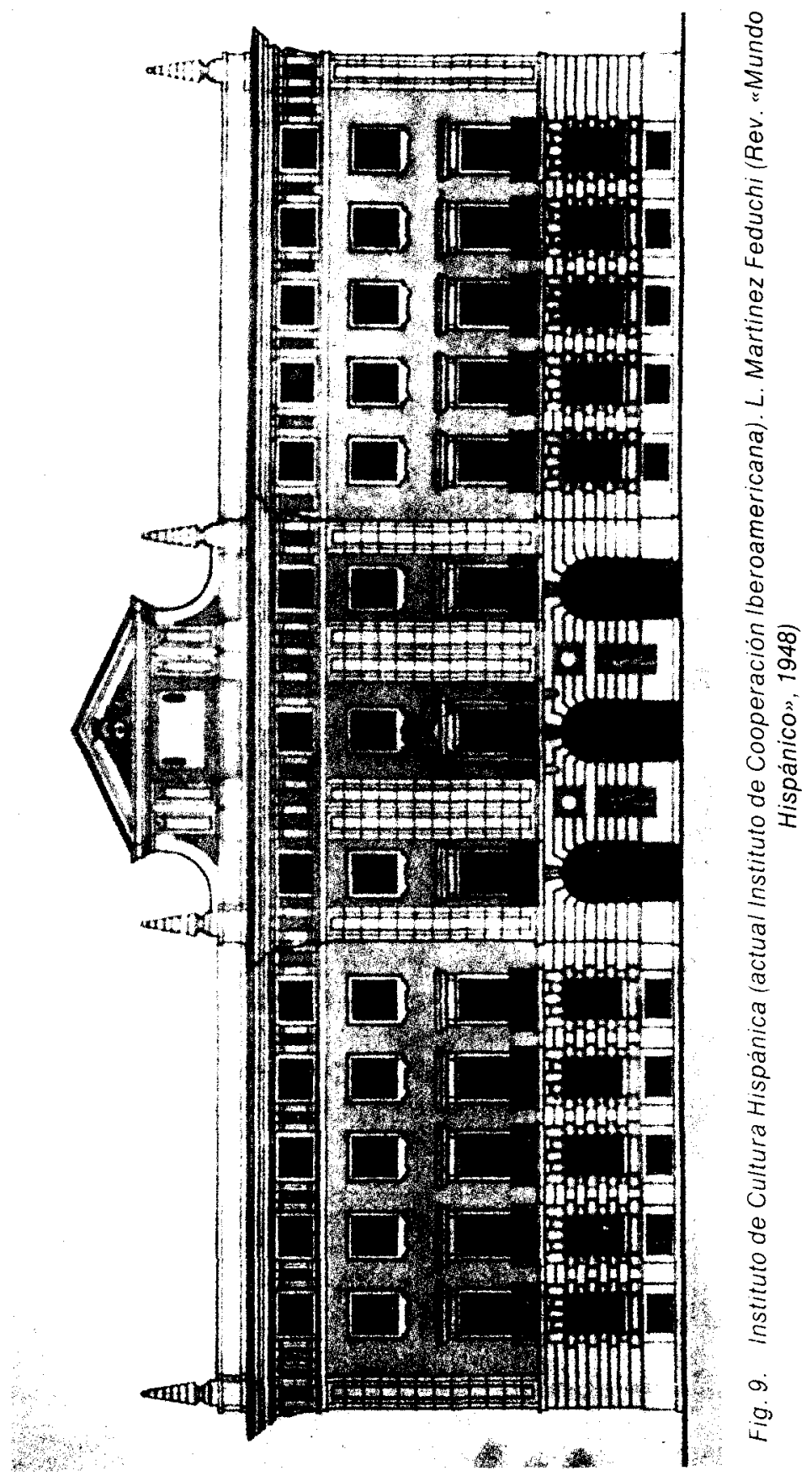


tral se realza además con el remate de un frontón triangular flanqueado por pináculos ${ }^{17}$. La obra, -según la prensa de la época- reunía "la grandeza, severidad y gracia» que requería un edificio de esta indole.

El Instituto no estaba concebido exclusivamente como un edificio que centralizase las actividades intelectuales y burocráticas, sino como algo mucho más importante: «La Casa de la Hispanidad, la casa solariega para todos los que, nacidos en la otra orilla del Atlántico, sientan la curiosidad intelectual o la necesidad sentimental de venir a conocer el solar de sus

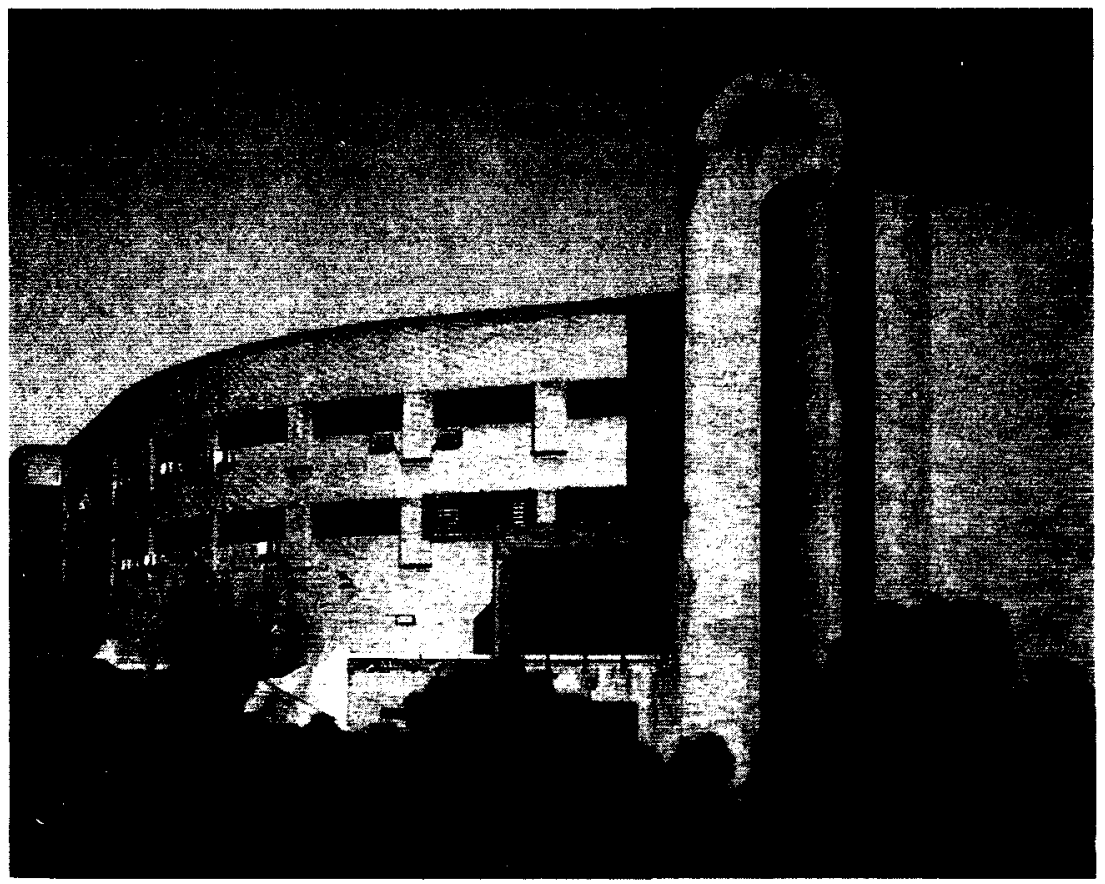

Fig. 10. Biblioteca del Instituto de Cooperación Iberoamericana. Arq.: A. Fernández Alba y J. L. Fernández del Amo. 1978.

${ }^{17}$ En 1974 se encargó al arquitecto A. Fernández Alba la ampliación del Instituto de Cultura Hispánica. Para cubrir las necesidades del ICH se proyectó una Biblioteca con dos conjuntos perfectamente diferenciados: la torre-silo, almacén de libros, y el edificio de la administración, lectura y servicios. El bloque macizo de la torre se complementa con un gran espacio abierto en las salas de lectura, creando un recinto interior tranquilo para las actividades de estudio. Con una estructura de hormigón, el cerramiento en ladrillo y las celosias en cemento blanco, tratan - según la Memoria del proyecto- de enlazar con el cercano Hospital Clinico, valorado como un "destacado ejemplo de buena arquitectura". (Fig. 10) 
mayores" ${ }^{18}$. Desde esta perspectiva se consideró que el proyecto de Feduchi, tanto por sus dimensiones, ornamentación y opción estilistica, «responde a la elevada misión espiritual y patriótica que representa".

Como acertadamente ha señalado $\mathrm{L}$. Delgado ${ }^{19} \mathrm{el} \mathrm{ICH}$, que sustituia en su labor al Consejo de la Hispanidad, restringía sus cometidos a afianzar los "vínculos espirituales" entre los pueblos que componen la comunidad Hispanoamericana, y se evitaba cuidadosamente la utilización de términos como "política" o "poder», presentes en la creación del Consejo de la Hispanidad, poniéndose el acento expresamente en cuestiones de indole cultural, tratando de desvanecer las susceptibilidades motivadas por su predecesor.

EI ICH debia ser el instrumento que abriera caminos y tendiera nuevos puentes para restablecer la comunicación fluida entre los paises hispanos.

Pero cabe preguntarse -como hace con gran perspicacia L. Delgado- si realmente los cometidos del $\mathrm{ICH}$ se ajustaban al carácter estrictamente cultural con que se presentaban a la luz pública, o era éste un mecanismo para favorecer, sin levantar inoportunos recelos, una acción de contenido más amplio.

Este autor, basándose en documentación del propio $\mathrm{ICH}$, afirma que las actividades no eran exclusivamente culturales, sino que, por el contrario, era un organismo esencialmente político al servicio de la vinculación de la vida española con la hispanoamericana en todos sus múltiples aspectos.

El 12 de octubre de 1951 se inaugura el edificio. El acto, presidido por el general Franco, coincidió con la apertura de la I Bienal Hispanoamericana de Arte, cuyos orígenes no son ajenos a la política de la Hispanidad ${ }^{20}$.

Las contaminaciones políticas con que nacieron las Bienales han sido subrayadas por un artista como Tápies que no duda en afirmar que el $\mathrm{ICH}$ creó las Bienales precisamente para ofrecer una "fachada de libertad" cultural de cara al exterior ${ }^{21}$.

18 Revista Mundo Hispánico, núm. 9, octubre de 1948.

19 Delgado, L., Op. cit., pág. 150.

20 Vid. Cabañas Bravo, M., "Introducción a la | Bienal Hispanoamericana de Arte", en Relaciones Artisticas entre España y América. C.S.I.C., 1990.

${ }^{21}$ TAPIES, A., Memoria personal. Fragmento para una autobiografia. Barcelona, Seix Barral, 1977. 
También Picasso era consciente de la posible manipulación politica que entrañaba la participación en la Bienal y advierte a los artistas de los diferentes paises de América acerca del contenido de tal invitación, el cual -afirma - «no es otro que el de una invitación a colaborar con el franquismo".

El último edificio de esta trilogía es el Colegio Mayor Nuestra Señora de Guadalupe. Proyectado en 1948 por Luis Martínez Feduchi, se sitúa en la Avenida de Séneca, en la zona destinada a este tipo de establecimientos.

La necesidad de los Colegios Mayores, como institución complementaria, se habia dejado sentir ya en la época de la Monarquia. Entonces se proyectó la Residencia de Estudiantes Hispanoamericanos en un estilo neocolonial. Era, por tanto, una vieja reivindicación del movimiento americanista, impulsada ahora por el Instituto de Cultura Hispánica, encargado de sufragar la instalación y el sostenimiento de la residencia.

El colegio se ofrecia especialmente a «estudiantes e investigadores de paises hispanoamericanos, Filipinas y Portugal, que acudan a ampliar sus estudios o a realizar investigaciones cientificas en España». Se deseaba que esta residencia tuviese una población mixta iberoamericana y española porque se creía que éste era el mejor sistema para "crear fuertes vinculos de afecto y ligazón con la realidad española".

El colegio de Nuestra Señora de Guadalupe tenía capacidad para 200 universitarios e investigadores. Una gran sala de conferencias constituia el eje del edificio. En cuatro pisos, y con la estructura cuadrangular, típica de los Colegios Mayores, se alinean las habitaciones dotadas de muebles claros y sencillos (fig. 11).

L. Martínez Feduchi, ya veterano proyectista de edificios relacionados con Hispanoamérica, y que - según una nota de prensa- «más ha contribuido en la hora presente al hallazgo de fórmulas arquitectónicas que fusionan modernidad y tradición", proyectó el edificio haciendo uso, de nuevo, de un lenguaje historicista (fig. 12).

Se alineaba asi con los arquitectos que, en los primeros años de la postguerra, trataron de configurar una arquitectura nacionat, que expresara el ideario de los vencedores en la guerra civil. El deseo de encontrar un estilo nuevo estuvo presente en los arquitectos más relacionados con el Régimen. Nunca pudieron llegar a formalizarlo, moviéndose a nivel teórico entre Herrera y Villanueva. Se defendía, en última instancia, el lenguaje historicista. 

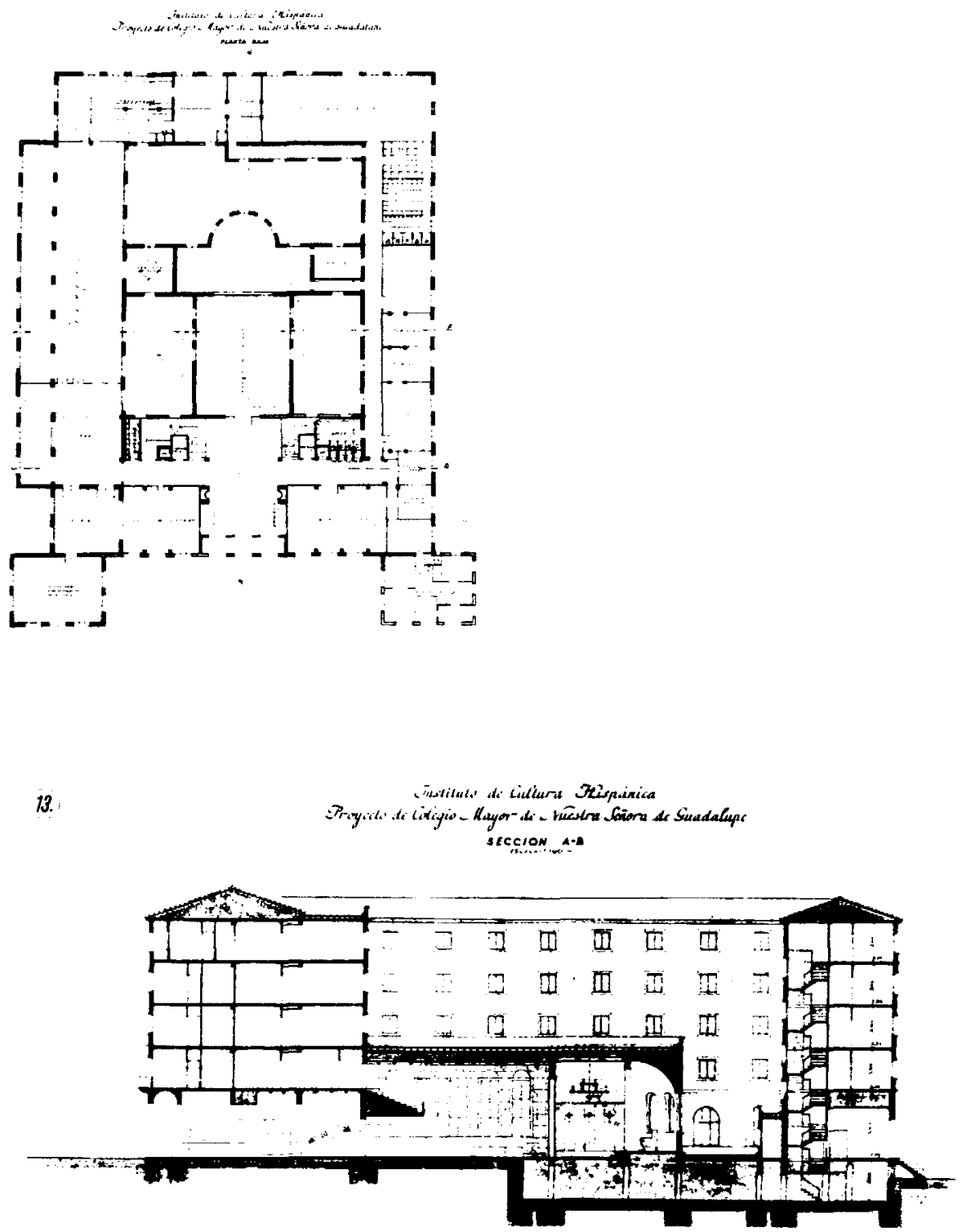

Fig. 11. Colegio Mayor Nuestra Señora de Guadalupe. Arquitecto L. Martinez Feduchi (Rev. "Mundo Hispánico») 


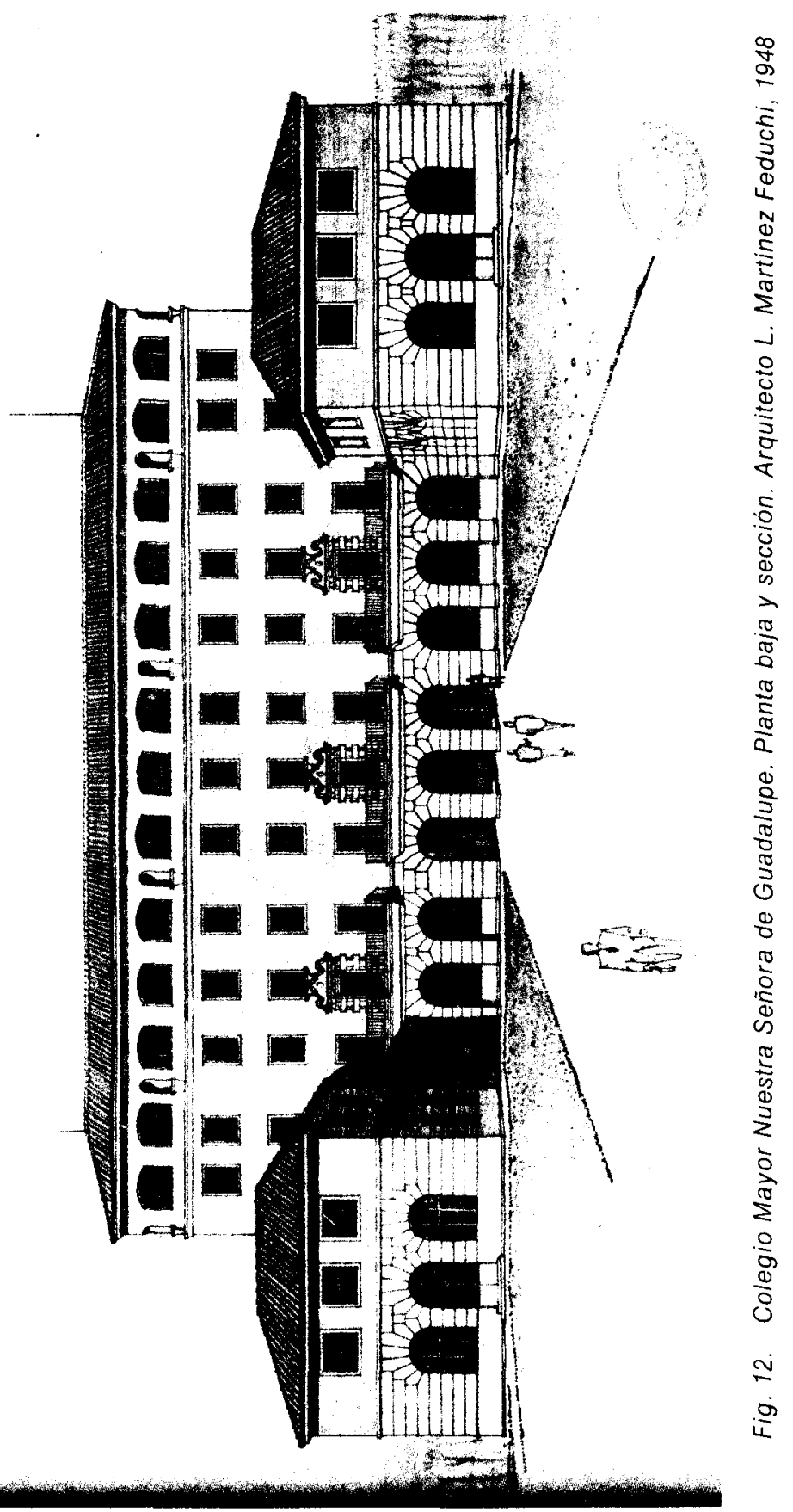

